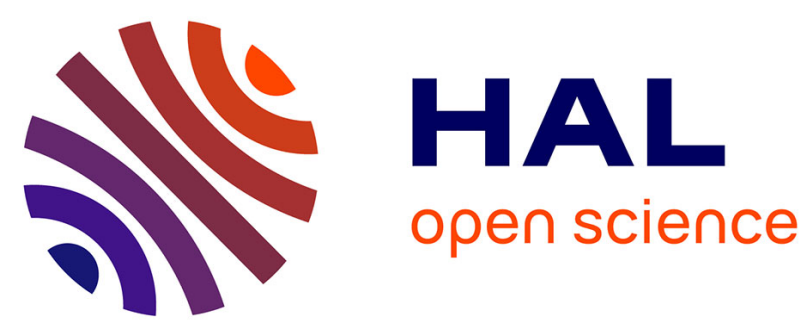

\title{
Bottom-up Construction of Xylan Nanocrystals in Dimethyl Sulfoxide
}

Zhuojun Meng, Daisuke Sawada, Christiane Laine, Yu Ogawa, Tommi Virtanen, Yoshiharu Nishiyama, Tekla Tammelin, Eero Kontturi

\section{To cite this version:}

Zhuojun Meng, Daisuke Sawada, Christiane Laine, Yu Ogawa, Tommi Virtanen, et al.. Bottom-up Construction of Xylan Nanocrystals in Dimethyl Sulfoxide. Biomacromolecules, 2021, 22 (2), pp.898906. 10.1021/acs.biomac.0c01600 . hal-03374611

\section{HAL Id: hal-03374611 \\ https://hal.science/hal-03374611}

Submitted on 12 Oct 2021

HAL is a multi-disciplinary open access archive for the deposit and dissemination of scientific research documents, whether they are published or not. The documents may come from teaching and research institutions in France or abroad, or from public or private research centers.
L'archive ouverte pluridisciplinaire HAL, est destinée au dépôt et à la diffusion de documents scientifiques de niveau recherche, publiés ou non, émanant des établissements d'enseignement et de recherche français ou étrangers, des laboratoires publics ou privés. 


\section{Bottom-up Construction of Xylan Nanocrystals in}

\section{Dimethyl Sulfoxide Solution}

Zhuojun Meng ${ }^{1}$, Daisuke Sawada ${ }^{1}$, Christiane Laine ${ }^{2}$, Yu Ogawa ${ }^{3}$, Tommi Virtanen ${ }^{2}$, Yoshiharu Nishiyama $^{3 *}$, Tekla Tammelin ${ }^{2 *}$, Eero Kontturi $^{1 *}$

${ }^{1}$ Department of Bioproducts and Biosystems, Aalto University, Espoo, Finland

${ }^{2}$ VTT Technical Research Centre of Finland, Espoo, Finland

${ }^{3}$ Univ. Grenoble Alpes, CNRS, CERMAV, 38000 Grenoble, France

KEYWORDS: hemicellulose, DMSO, nanocrystals, crystallization

ABSTRACT. A new type of a polysaccharide (hemicellulose) nanocrystal, bearing the shape of an anisotropic nanoflake, emerged from a dimethylsulfoxide (DMSO) dispersion of woodbased xylan through heat-induced crystallization. The dimensions of these xylan nanocrystals were controlled by the crystallization conditions. Sharp signals in solid state NMR indicated a well-ordered crystal structure. The unit cell is constituted of two asymmetric xylose residues and DMSO molecules resided in a host-guest type of arrangement with more than one local environment. The homogeneity between xylan and DMSO was evident within a size scale of $50 \mathrm{~nm}$. X-ray and electron diffraction indicated a 2-fold helical helix along the chain in a monoclinic unit cell with an antiparallel arrangement, with chains placed on the 2-fold helix axes: at the corner and at the center. The 2-fold helical structure is unique for xylan for which only 3-fold helical form has been reported. The DMSO molecules participated in the 
crystallization and they were shown to be vital in stabilizing the crystalline structure. The manipulation of temperature, concentration and incubation time of xylan/DMSO dispersion provided pathways for the crystallization to form size-adjustable nanocrystals. As $20-30 \%$ of biomass consists of hemicellulose, this work will serve as a starting point to understand the controlled assembly of hemicellulose to discover its full application potential.

\section{INTRODUCTION}

Polysaccharides are an important class of bio-based materials that have attracted significant research interest due to their assured availability, biocompatibility and degradability. ${ }^{1,2,3}$ In terms of nanomaterials, intensive exploration and research in the past few decades have been directed to nanocrystals based on natural polysaccharides, such as cellulose, ${ }^{4,5,6}$ chitin $^{7}$ and starch. ${ }^{8,9}$ They have been widely used in advanced functional materials, such as fiberreinforcing composites, ${ }^{10,11,12}$ biomimetic composites, ${ }^{13,14}$ biological scaffolds, ${ }^{15}$ biosensors, ${ }^{16,17,18}$ advanced films, ${ }^{19}$ hydrogels ${ }^{20,21}$ and drug delivery vectors. ${ }^{22,23}$ However, hemicellulose, a major part of lignocellulosic biomass, ${ }^{24}$ has not been investigated from the point of view of nanocrystals and - although they do exist - even the reports on its crystallization are scarce. ${ }^{25,26,27,28,29,30}$ Hemicellulose is generally considered to be amorphous due to the side groups ${ }^{31}$ and therefore, its proposed applications have been mainly in bulk applications, for example, films for packaging and coating. ${ }^{32,33,34}$ The difficulty to construct controlled, nano-sized crystalline structures, such as rods or fibrils, from hemicellulose has largely impeded its use in more sophisticated materials applications so far.

Xylan is the main hemicellulose in hardwood with a backbone composed of partly acetylated $\beta-1,4$ linked D-xylose residues substituted to a low degree with 4- $O$-methyl- $\beta$-D-glucuronic 
acid groups. ${ }^{35,36}$ Alkali-extraction from hardwood pulp combined with filtration or precipitation techniques has been demonstrated to yield pure deacetylated xylan. This type of xylan is scarcely soluble in water and most solvents. ${ }^{35}$ In this study, we produced xylan nanocrystals (XyNCs) with controlled dimensions through crystallization from a xylan/dimethylsulfoxide (DMSO) dispersion. This novel bottom-up approach offers a new insight to the controlled preparation of polysaccharide-based nanoparticles whose dimensions in the bulk of the current literature are predominantly dictated by the biological source due to the top-down isolation techniques.

\section{RESULTS AND DISCUSSION}

Figure 1 presents the method to produce hemicellulose nanocrystal through a bottom-up approach from natural resources. The pure and essentially linear xylan used in this study was isolated from bleached birch kraft pulp by alkaline extraction (Figure S1A). ${ }^{35}$ To prepare the nanocrystals, xylan was dispersed in DMSO by using magnetic stirring at $60{ }^{\circ} \mathrm{C}$ (Figure S1B). 


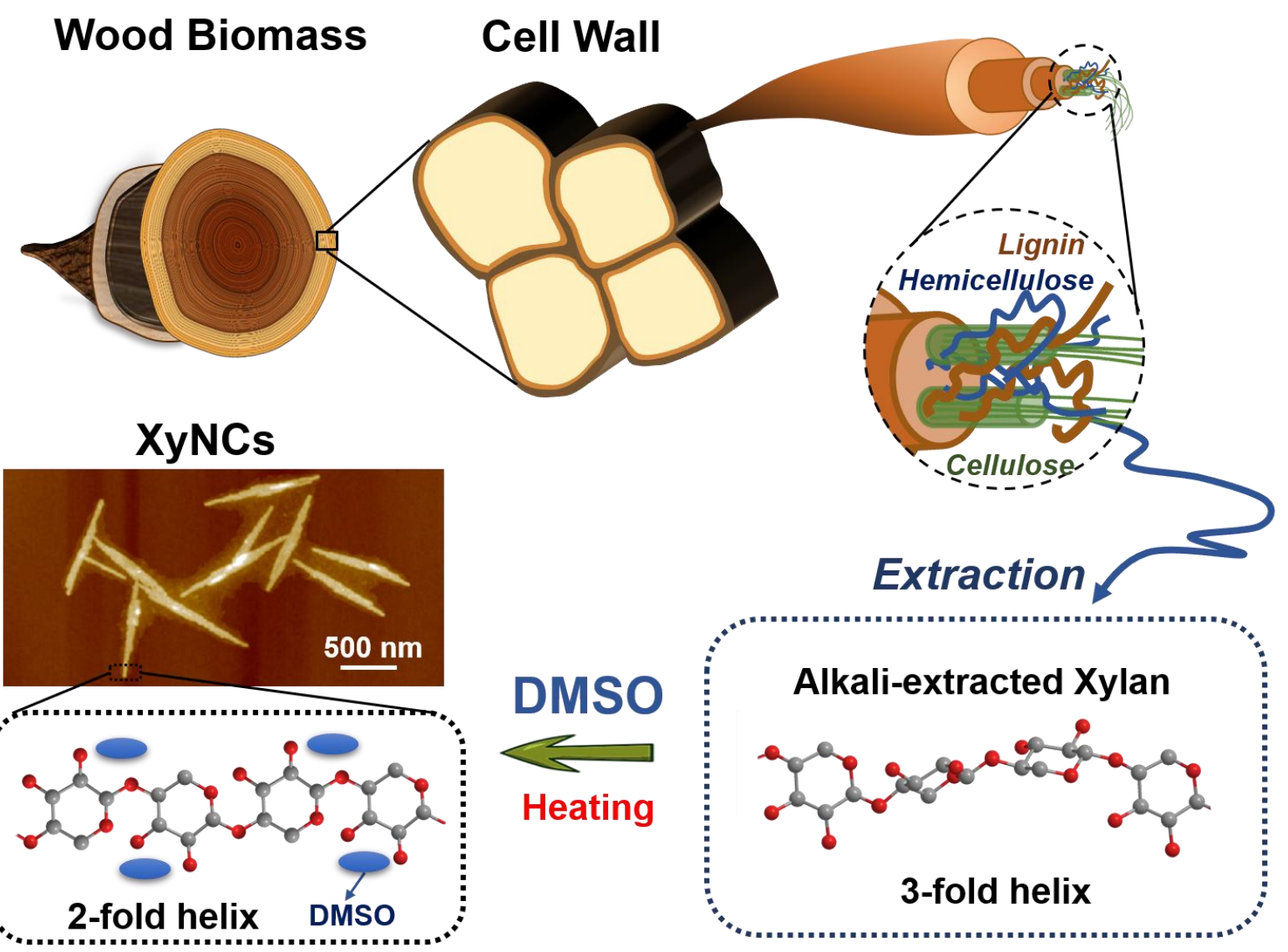

Figure 1. Scheme illustrating the preparation of hemicellulose nanocrystal from wood biomass.

After suspending xylan in DMSO at $60{ }^{\circ} \mathrm{C}$ for 10 days, an elongated flake-like structure was observed under AFM imaging (Figure 2A), similar to precipitates of low molecular weight cellulose $^{37,38}$ or mannan ${ }^{29,30}$. The anisotropic shape of the nanostructure is due to a faster growth along one direction. Figure 2B reveals that the nanoparticles formed in DMSO are homogeneous with a relatively narrow length distribution of $855 \pm 40 \mathrm{~nm}$. The transmission electron micrographs (TEM) showed similar objects (Figure 2C). Since both conventional AFM and TEM detect structures in the dried state, Cryo-TEM was employed to observe in the suspension state to avoid possible artefacts induced by drying (Figures S2). Cryo-TEM 
images show that XyNCs with dimensions similar to TEM and AFM images, embedded in vitrified DMSO.

Height profiles taken perpendicular to the elongated objects on an AFM image in Figure 2D gives the height of $10 \mathrm{~nm}$ width of $100 \mathrm{~nm}$. As the tip radius of AFM is less than $10 \mathrm{~nm}$, the effect of convolution would be limited. The height seems to be tapered at the border, with diffuse substance extending for another $100 \mathrm{~nm}$. The roughness of the top surface of the crystal was $0.62 \mathrm{~nm}$ (Figure S3) roughly corresponding to the size of a residue. The gel permeation chromatography (GPC) of the xylan from the precipitate (Figure 2E) gave weight average molecular weight $\left(\mathrm{M}_{\mathrm{w}}\right)$ of $18,990 \mathrm{~g} \mathrm{~mol}^{-1}$, number average molecular weight $\left(\mathrm{M}_{\mathrm{n}}\right)$ of $12,250 \mathrm{~g} \mathrm{~mol}^{-1}$ and polydispersity index of 1.55 . Based on the $\mathrm{M}_{\mathrm{W}}$ of xylan in XyNCs (Figure 2D) and molecular weight of xylose repeating unit, as xylose contributes more than $96 \%$ of composition (Table S2), the corresponding degree of polymerization $\left(\mathrm{DP}_{w}\right)$ of the xylan chain is 128 .
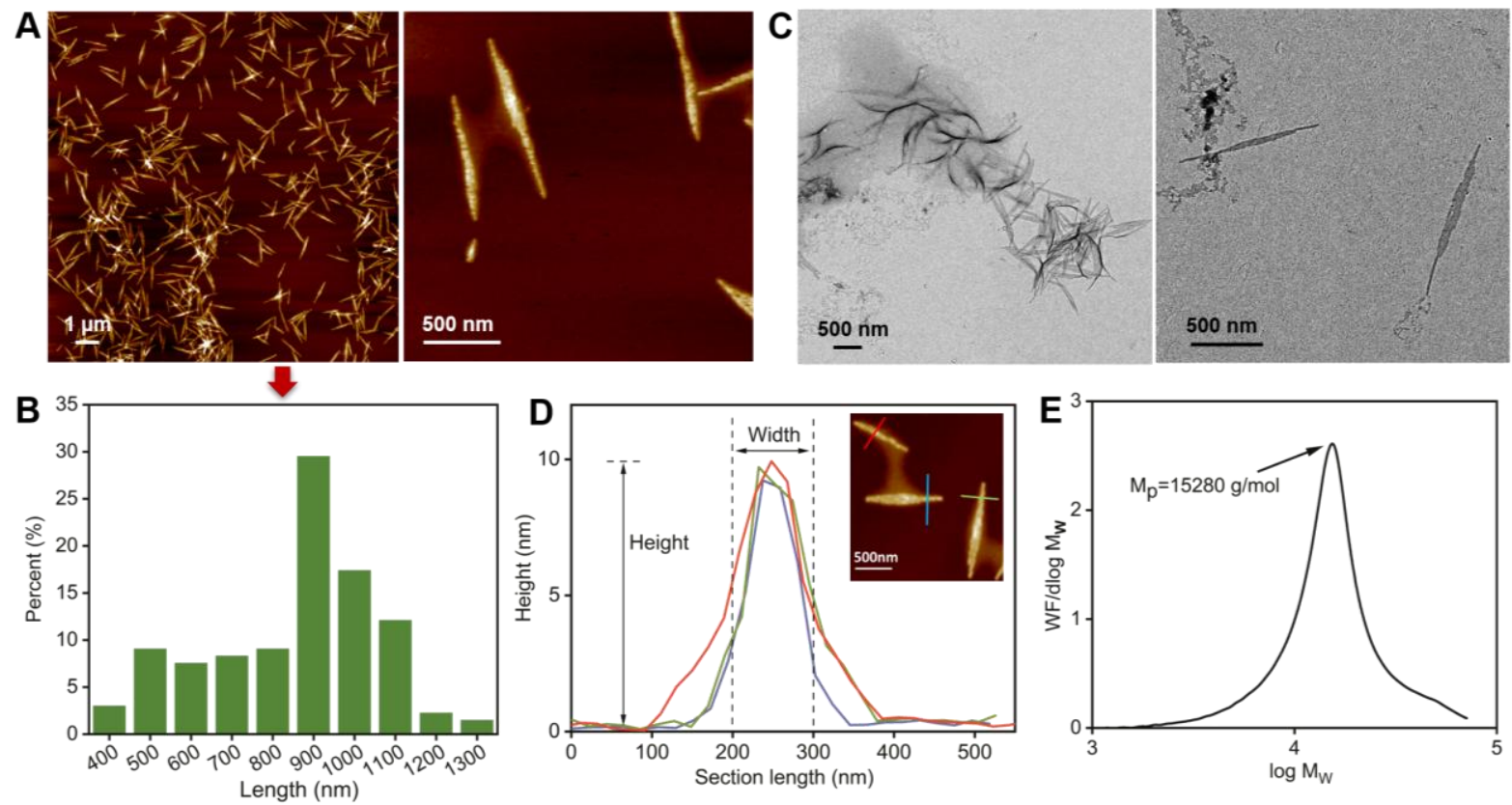
Figure 2. General morphology and dimensions of xylan crystallized from $5 \mathrm{mg} \mathrm{ml}^{-1}$ in DMSO at $60{ }^{\circ} \mathrm{C}$ for 10 days. (A) AFM height image showing the xylan crystals grown from xylan/DMSO dispersion and spin coated on silicon wafer. (B) Length distribution histogram estimated from AFM image. (C) TEM images of the xylan crystals on carbon coated copper grids. (D) Height profile perpendicular to the needle like morphology with the corresponding AFM image in the inset, with the color lines indicating the trace for the profile. Molecular weight distribution of xylan re-dissolved from nanocrystals.

The ${ }^{13} \mathrm{C}$ CP/MAS-NMR of raw xylan as received (Figure S4A) gives three resonance peaks at 62,73 , and $100.4 \mathrm{ppm}$ with intensity ratio of 1:3:1 (Table 1). These are assigned to C5, an overlapped contribution of $\mathrm{C} 2,3,4$, and $\mathrm{C} 1$ (Figure $3 \mathrm{~A}$, red line). ${ }^{39}$ On the other hand, the lyophilized XyNCs (Figure S4B) show well-resolved spectra with typical signal linewidths of $0.7 \mathrm{ppm}$ (full width at half maximum, Figure $3 \mathrm{~A}$, blue line), which is considerably sharper than the linewidths for the amorphous starting material (2.9 ppm). In the XyNCs spectra, C1 (centered at $103 \mathrm{ppm}), \mathrm{C} 4(80 \mathrm{ppm})$, and C5 (61 ppm) show splitting into two peaks of equivalent intensity (Table 1). Another important feature is the large shift of $\mathrm{C} 1$ by $3 \mathrm{ppm}$ and $\mathrm{C} 4$ by $8 \mathrm{ppm}$ towards the lower magnetic field, indicating an unshielding of the carbon due to conformational strain compared to the amorphous or solution. The splitting of the signals suggests that two asymmetric xylose residues make up a crystallographic unit cell, in a similar fashion to glucose residues in cellulose $\mathrm{I}_{\beta}$ and II. $^{40,41,42}$ The DMSO gave two signals centered at 39 ppm suggesting that DMSO has more than one well defined local environment. The proton $T_{1}$ relaxation time, measured with a standard inversion recovery experiment, was $0.9 \mathrm{~s}$ for both xylan and DMSO (Figure S5), suggesting homogeneity between xylan and DMSO within a size scale of $50 \mathrm{~nm} .{ }^{43,44}$ Moreover, the single pulse NMR spectrum (Figure 
S6) clearly shows the presence of disordered xylan in the crystal sample although its quantification is out of reach.

3-fold helical structure is considered to be the most stable conformation for xylan in solution (one turn per three glycosidic bonds). ${ }^{45}$ Also xylan crystallized from aqueous system forms 3fold helix. ${ }^{25,27}$ Significantly, 2-fold helical xylan (one $360^{\circ}$ twist per 2 glycosidic bonds) has been observed only through the interaction with cellulose surface. ${ }^{46,47}$ Chemical shifts of $\mathrm{C} 1$ and $\mathrm{C} 4$ resonances have been shown to be most sensitive towards changes in glycosidic torsional angles, with approximately 3 and 5 ppm higher chemical shift for $\mathrm{C} 1$ and $\mathrm{C} 4$ in the case of 2-fold helix compared to that of 3 -fold. ${ }^{48}$ This corresponds to the observed difference in the chemical shifts of $\mathrm{C} 1$ in raw xylan (centered at $100 \mathrm{ppm}$ ) and the xylan precipitates (103 ppm). The signal from C4 in raw xylan is almost completely overlapped with signals from $\mathrm{C} 2$ and $\mathrm{C} 3$, but appears at $\mathrm{C} 4$ close to $80 \mathrm{ppm}$ in the crystals, which is in accordance with the assignment for 2-fold helix for xylan associated with a cellulose crystal, as described by Simmons et al. ${ }^{46}$

The thermogravimetric analysis (TGA) of the xylan precipitates (Figure 3B) shows two major weight losses $\left(189{ }^{\circ} \mathrm{C}\right.$ and $\left.277{ }^{\circ} \mathrm{C}\right)$ during the pyrolysis process. The weight loss at $277{ }^{\circ} \mathrm{C}$ stands for the degradation of xylan as only water and carbon dioxide are released (Figure S7A). The weight loss peak at $189{ }^{\circ} \mathrm{C}$ was associated with the volatilization and partial degradation of DMSO (Figure S7B). 

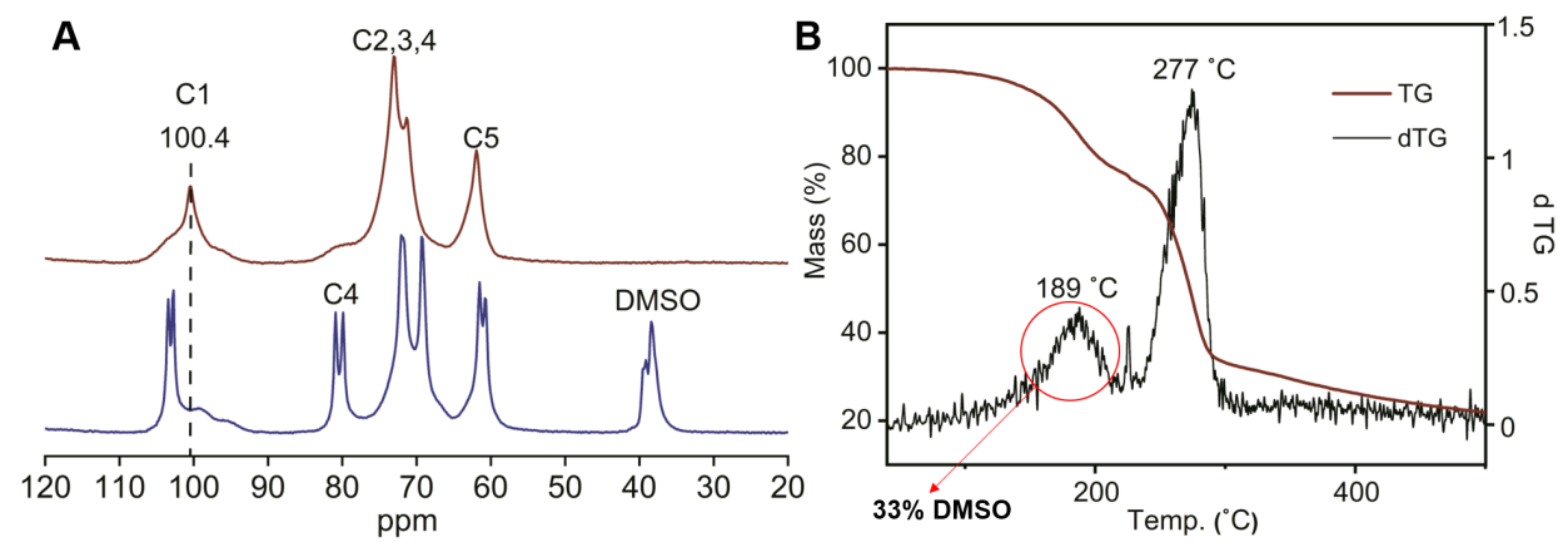

Figure 3. (A) ${ }^{13} \mathrm{C} \mathrm{CP/MAS} \mathrm{solid-state} \mathrm{NMR} \mathrm{spectra} \mathrm{of} \mathrm{amorphous} \mathrm{xylan} \mathrm{(top,} \mathrm{red)} \mathrm{and} \mathrm{xylan}$ crystals precipitated in DMSO (bottom, blue). Peaks close to $40 \mathrm{ppm}$ are from DMSO. (B) TGA and DTG curves of the xylan crystals.

Table 1. Table of NMR peak positions for raw xylan and xylan crystals in Figure 3A.

\begin{tabular}{|c|c|c|c|c|c|}
\hline \multirow{3}{*}{ Raw Xylan } & \multicolumn{5}{|c|}{${ }^{13} \mathrm{C}$-chemical shift, PPM } \\
\hline & $\mathrm{C} 1$ & \multicolumn{2}{|c|}{$\mathrm{C} 2,3,4$} & \multicolumn{2}{|l|}{$\mathrm{C} 5$} \\
\hline & 100.4 & \multicolumn{2}{|c|}{73,71} & 62 & \\
\hline \multirow{2}{*}{$\mathrm{XyNCs}$} & $\mathrm{C} 1$ & $\mathrm{C} 2,3$ & $\mathrm{C} 4$ & $\mathrm{C} 5$ & DMSO \\
\hline & 103.4102 .7 & 7269 & 80.979 .9 & $61.5 \quad 60.8$ & $39 \quad 38.4$ \\
\hline
\end{tabular}

Electron diffraction gave single crystalline diffraction patterns, showing that each object in the precipitate is in fact a single nanocrystal, and the X-ray diffraction of the mat of precipitates indicates that the ensemble of precipitates has relatively high crystallinity, as the halo from amorphous substance is low compared to the crystalline peaks. The unit cell parameters of the xylan crystals were determined by the combination of electron diffraction and X-ray diffraction shown in Figure $4 \mathrm{~A}$ and $4 \mathrm{~B}$. The base plane diffraction of a single crystal gave a parallelepiped lattice with principal vectors $v^{*}{ }_{1}$ and $v^{*}{ }_{2}$ with length of $0.203 \AA^{-1}$ and $0.108 \AA^{-1}$, resulting in an angle of $67^{\circ}$. This would correspond in real space vector $v_{1}$ and 
$v_{2}$ of $5.39 \AA$ and $10.1 \AA$, leading to an angle of $113^{\circ}$ and an area of $50 \AA^{2}$. The lattice period along the long axis of the crystal of about $5 \AA$ is slightly higher than the typical spacing in close packing of pyranose rings in cellulose $(\sim 4 \AA)$ but are similar to $\beta$-chitin hydrates $(4.8$ $\AA) .{ }^{49}$ The pyranose ring is probably roughly perpendicular to the growth direction but swollen by the insertion of DMSO molecules, as the lattice dimension perpendicular to the growth direction is much larger. Separately, exhaustive search approach assuming a monoclinic unit cell to explain the positions of X-ray diffraction resulted in 8 possible candidates (Table S3). The size of the unit cell in $a b$ plane obtained from X-ray diffraction data is about double the unit obtained in electron diffraction, and the c-axis is roughly $10 \AA$, which is a typical value for 2-fold helical structure of $\beta-1,4$ polysaccharides.

The unit cell volume is $1017 \AA^{3}$. Considering two asymmetric units in a unit cell indicated by ${ }^{13} \mathrm{C} C P / M A S-N M R$, the unit cell should contain minimum of two xylan chains. To estimate the number of DMSO molecules in the unit cell, we assumed a unit volume for the xylose residue in xylan to be between $145 \AA^{3}\left(1.51 \mathrm{~g} \mathrm{~cm}^{-3}\right)$ and $135 \AA^{3}\left(1.62 \mathrm{~g} \mathrm{~cm}^{-3}\right)$, and a unit volume for a single DMSO molecule to be $118 \AA^{3}\left(1.1 \mathrm{~g} \mathrm{~cm}^{-3}\right){ }^{50,51}$ Then the unit cell volume having four xylose residues with a solvation of 4 DMSO molecules would be in the range of 1012-1052 $\AA^{3}$, with the lower bound agreeing with the experimental unit cell $\left(1017 \AA^{3}\right)$. Thus, there would be 1:1 stochiometry between xylose residue DMSO molecule in the unit cell. The corresponding weight fraction of DMSO is $33 \%$, consistent with the weight loss below $200{ }^{\circ} \mathrm{C}$ in TGA (Figure 3B).

Because $a b$ projection appears as a base-plane electron diffraction pattern and because the $\mathrm{X}$ ray diffraction intensities of $h k l$ with a higher number of 1 appear stronger in reflection mode than in transmission mode (Table S4), this indicates that the thickness direction of the crystal corresponds to the $c$-axis. Since the molecular contour length of $64 \mathrm{~nm}$ estimated from GPC 
is much longer than the crystal thickness of $10 \mathrm{~nm}$ (Figure 2D), the only conceivable conclusion is that the crystals should involve chain folding which is not common in $\beta-1,4-$ glucans. $^{26,52}$ The propensity of xylan to form single crystals upon bottom up construction from DMSO is distinct from the top-down isolated bio-based crystals such as cellulose nanocrystals which are always polycrystalline. ${ }^{53}$ Single crystal character allows, for example, the build-up of super crystals which cannot be obtained from polycrystalline materials. Finally, a proposed unit cell and packing model of xylan nanocrystals is presented in Figure 4C. Possible chain folding and molecular packing in the unit cell are illustrated in Figure 4D and Figure 4E. Xylan chains are packed in an antiparallel manner into monoclinic unit cells that are in turn perpendicularly packed in the longitudinal direction in the anisotropic nanocrystals.

A

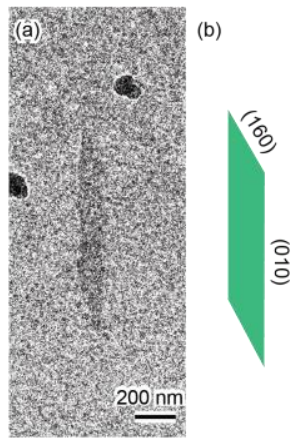

C

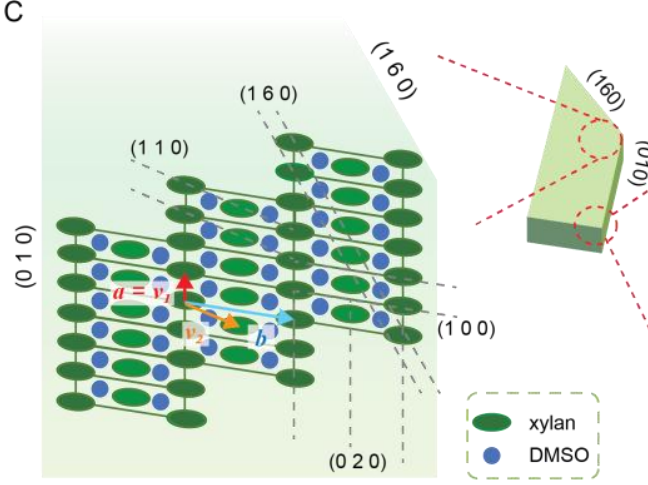

B

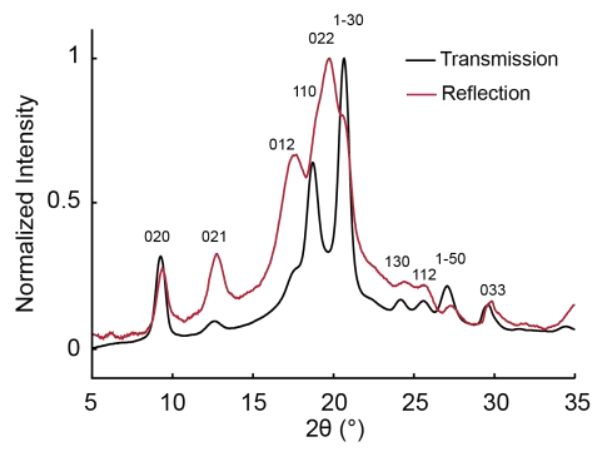

D E

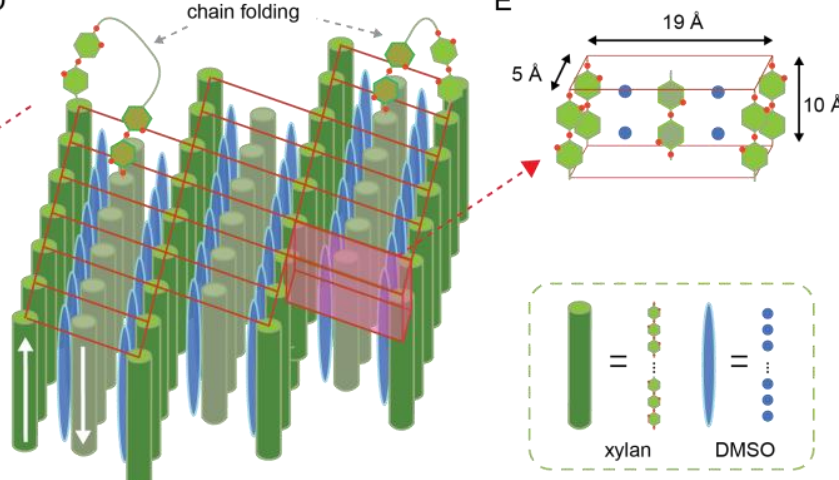

Figure 4. (A) (a) Diffraction contrast image of XyNC in thin frozen DMSO layer. (b) Schematic illustration of crystal. (c) Selected area diffraction pattern taken from the crystal in 
(a). Three-digit indices $(h k l)$ are based on the X-ray unit cell and two-digit ones $(h k)$ are based on the sub cell obtained from the electron diffraction. The reciprocal vectors of the unit cell $\left(a^{*}, b^{*}\right)$ are indicated with those of the sub cell $\left(v^{*}{ }_{1}\right.$ and $\left.v^{*}\right)$. (B) X-ray diffraction profile of XyNC sheets in transmission (black) and reflection modes (red). (C-E) Schematic illustrations of the molecular packing in $\mathrm{XyNC}$ in the two-dimensional projection onto the lamellar plane (C) and in the three-dimensional view (D). Real-space vectors of the unit cell $(a, b)$ and the sub cell $\left(v_{1}, v_{2}\right)$ are shown as solid arrows in $(\mathrm{C})$. Examples of possible chain folding are illustrated in (D). Two colors of xylan molecules denote the molecules with different molecular polarities. (E) Molecular packing in the unit cell.

DMSO is reported to promote the nucleation of proteins in water by increasing the solubility and decreasing the enthalpy of crystallization. ${ }^{54}$ However, DMSO molecules included as a genuine component in a biomolecule-based crystal have rarely been reported. ${ }^{55}$ When the xylan nanocrystals were rinsed with water (Figure S9), the xylan remains insoluble but the morphology was destroyed into much finer fibrillar objects. All DMSO were removed by simple rinsing, as there is no weight loss below $200{ }^{\circ} \mathrm{C}$ in the thermogravimetric analysis (Figure S10). Ethanol and acetone rinsing can also remove the DMSO. Although the diffraction pattern of the dried sample after rinsing with ethanol or acetone is much broader, the profile is different from raw amorphous xylan and the structural history was not completely lost (Figure S11). Nevertheless, the presence of DMSO is crucial in stabilizing the crystal structure.

When the crystallization proceeded at $60{ }^{\circ} \mathrm{C}$ in $5 \mathrm{mg} \mathrm{ml}^{-1}$ xylan concentration, the dimensions of the crystals remained almost monodisperse, monotonically increasing with time (Figure 5A), from $200 \mathrm{~nm}$ to $850 \mathrm{~nm}$ and remained relatively constant after 10 days (Figure S12). Meanwhile, the thickness remained relatively constant over time with only slight increase 
(Figure S13). With the same xylan concentration $\left(5 \mathrm{mg} \mathrm{ml}^{-1}\right)$, the crystallization rate at room temperature (RT) was much slower than at $40{ }^{\circ} \mathrm{C}$ or $60{ }^{\circ} \mathrm{C}$ (Figure $\left.5 \mathrm{~B}\right)$. However, when xylan was incubated in DMSO at $80{ }^{\circ} \mathrm{C}$, no crystal formation was observed, suggesting that there is an optimum window for crystal growth.

It is unlikely that the method presented here would represent the only feasible routes to XyNCs. Further systematic fundamental studies may include, for example, the effect of solvent or chemical modification of xylan once the appropriate condition windows and constraints for nanoparticle formation have been found in different systems. Controlling the rather monodisperse length of XyNCs is an important asset here when compared to cellulose nanocrystals where the length is always polydisperse and can be poorly controlled. ${ }^{53}$ 
A
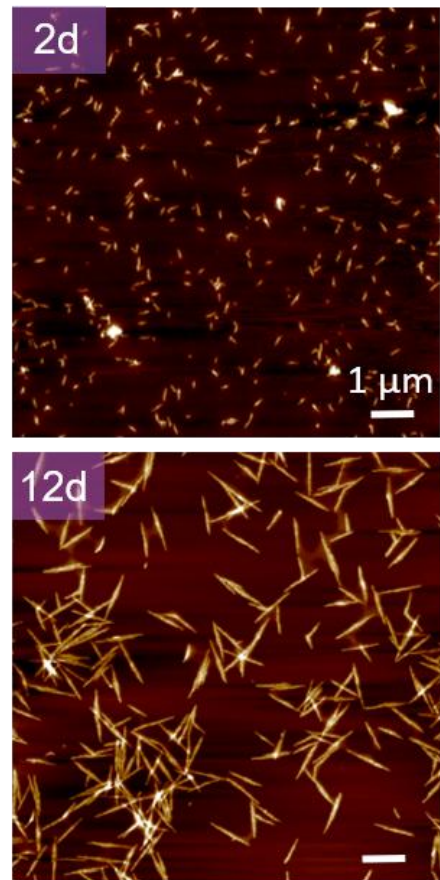

$\mathrm{B}$
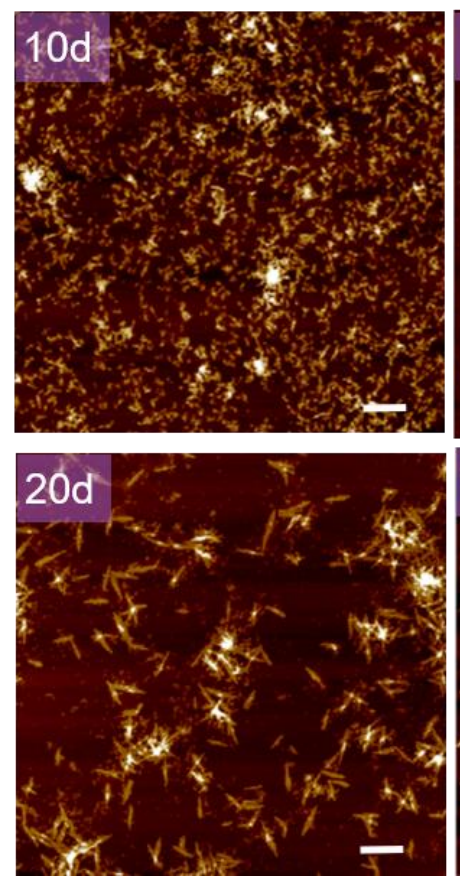

$60{ }^{\circ} \mathrm{C}$
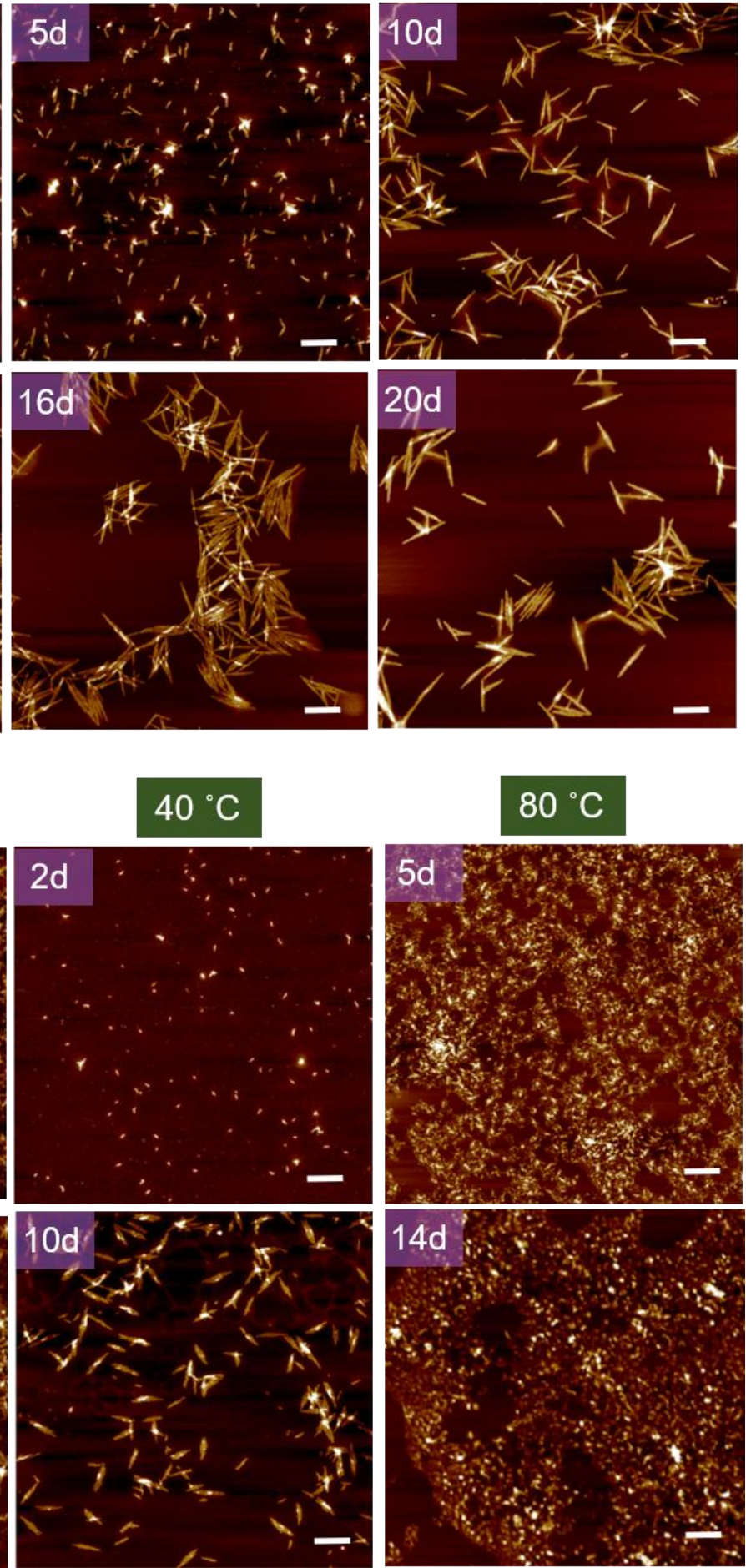

Figure 5. AFM height images of xylan nanocrystal precipitates as function of temperature and duration of crystallization. Samples were spin coated onto a silicon wafer substrate. (A) At $60{ }^{\circ} \mathrm{C},(\mathrm{B})$ at room temperature, $40{ }^{\circ} \mathrm{C}$ and $80{ }^{\circ} \mathrm{C}$. The xylan concentration was $5 \mathrm{mg} \mathrm{ml}^{-1}$. 


\section{CONCLUSIONS}

A novel hemicellulose nanocrystal was obtained in the shape of an anisotropic flake composed of xylan, forming crystallosolvates with DMSO. The crystal growth direction was in the direction perpendicular to the pyranose plane, which is similar to the crystallization behavior of cellulose oligomers ${ }^{56}$ or chitin oligomers ${ }^{49}$ in aqueous system. The molecular weight of xylan measured by dissolving the nanocrystals were much higher than the thickness of the crystals, implying chain folding in the crystals. ${ }^{52}$ Xylan/DMSO dispersions provided pathways for the crystallization to form size-adjustable xylan nanocrystals. The crystal consists of two asymmetric xylose residues in a two-chain monoclinic unit cell with $a=$

$5.131 \AA, b=19.415 \AA, c=10.32 \AA$ and $\gamma=98.9^{\circ}$ with space group $\mathrm{P} 2{ }_{1}$. The $\mathrm{C} 4$ chemical shift at $80 \mathrm{ppm}$ and the unit cell supports a 2-fold helical structure of xylan. When DMSO was removed by water, ethanol or acetone, the integrity of the crystal was lost, indicating that DMSO is crucial in stabilizing the crystalline structure. These are new insights into the structure of hemicellulose, leading to a new platform for hemicellulose-based materials, such as biomimetic toughening, drug delivery, biosensors and bioactive systems. It also serves as an indicator to point out that the full potential of biomass components is far from being fulfilled at present.

\section{EXPERIMENTAL SECTION}

Materials. DMSO (assay $\geq 99.9 \%$ ) was purchased from Sigma-Aldrich (St. Louis, United States) and used without further purification. Alkaline xylan was isolated as reported by Laine et al. ${ }^{35}$ Commercially bleached birch kraft pulp from a Finnish pulp mill was extracted at a consistency of $4 \%$ using $1 \mathrm{M} \mathrm{NaOH}$. After $1 \mathrm{~h}$ extraction, the filtrate containing the extracted xylan was separated from the fibers using a decanter centrifuge followed by bag filtration $(10 \mu \mathrm{m})$. The microfiltered extract was concentrated by ultrafiltration using a spiral 
membrane unit with a nominal cut-off of $10 \mathrm{kDa}$ (Alfa-Laval 6.3-3 PN, Spiral Gross-Flow, surface area $15 \mathrm{~m}^{2}$ ). Then, the concentrate was diluted with water and diafiltration was performed for concentration with the same setup as in the ultrafiltration. This step was repeated until the conductivity of the permeate was below $1 \mathrm{mS} \mathrm{cm}^{-1}$.

The extract was freeze-dried after filtration. The carbohydrate composition including neutral and acidic sugars was determined by methanolysis. ${ }^{57,58}$ Briefly, $2 \mathrm{~mL}$ of water-free acidic methanol and $10 \mathrm{mg}$ of dry sample were mixed in a $10 \mathrm{~mL}$ test tube and placed in an oven at $105{ }^{\circ} \mathrm{C}$ for $3 \mathrm{~h}$. After cooling, pyridine was added to the mixture and mixed thoroughly. Subsequently, sorbitol was added and the mixture was freeze-dried overnight, followed by derivatization in $\mathrm{N}, \mathrm{O}$-bis(trimethylsilyl)-trifluoroacetamide (BSTFA) and trimethylsilyl chloride (TMCS). After centrifugation, the clear sample solution was analyzed by GC-MS and quantified by GC-FID. Various sugars, i.e., L-arabinose, D-xylose, D-glucose, D-mannose, and D-galactose, were used as calibration substances with sorbitol as an internal standard. Correction factors for individual sugars were gained from the calibration and utilized accordingly when calculating the sugar ratios from the relative peak areas in the chromatograms of the actual sample. The GC-MS identification was performed with a Shimadzu GCMS-QP2010Plus and the GC-FID analysis with a Shimadzu GC-2010 Plus GC. A ZB-1HT column $(20 \mathrm{~m} \times 0.18 \mathrm{~mm}$ i.d. $\times 0.18 \mu \mathrm{m}$ film thickness $)$ was used on both devices.

Xylan nanocrystals preparation. Xylan was dispersed in DMSO to give a desired xylan concentration. The samples were heated in silicon oil bath with magnetic stirring. The process of crystallization was monitored with atomic force microscopy (AFM). 
Atomic Force Microscopy (AFM). Xylan/DMSO dispersion was centrifuged for $5 \mathrm{~min}$ at 10,000 rpm at room temperature, using Eppendorf Minispin (Sigma-Aldrich, St. Louis, United States) to separate aggregated crystals. Then the supernatant was spin coated on a silicon wafer by using a WS-650SX-6NPP/LITE spin coater (Laurell Technologies Corporation, North Wales, PA). Before spin-coating, the silicon wafers were first cleansed for 15 min in a UV-ozonator (Bioforce Nanosciences Inc., CA). Spin-coating was carried out at $4000 \mathrm{rpm}$ with an acceleration of $4000 \mathrm{rpm} \mathrm{s}^{-1}$ for approximately 2 minutes. AFM was carried out with a MultiMode 8 Scanning Probe Atomic Force Microscope from Bruker AXS inc. (Madison, WI). Images were taken using an $\mathrm{E}$ scanner in tapping mode with NSC15/AIBS silicon cantilevers by Ultrasharp $\mu$ masch (Tallinn, Estonia). According to the manufacturer, the radius of curvature of the tips was less than $10 \mathrm{~nm}$ with a typical cantilever resonance frequency of $325 \mathrm{kHz}$. AFM images were analyzed using Nanoscope Analysis 1.20 software.

Solid State-NMR. Lyophilized xylan crystals were prepared from xylan/DMSO mixture with a freeze-dryer (Martin Christ Gefriertrocknungsanlagen $\mathrm{GmbH}$ ) for 10 days. The ${ }^{13} \mathrm{C}$ crosspolarization (CP) magic angle spinning (MAS) NMR measurements were performed using an Agilent DD2 600 NMR spectrometer with magnetic flux density of $14.1 \mathrm{~T}$, equipped with a 3.2 mm T3 MAS NMR probe operating in a double resonance mode. Samples were packed in $\mathrm{ZrO}_{2}$ rotors, MAS rate in experiments was set to $10 \mathrm{kHz} .8000$ scans were accumulated using a $1.3 \mathrm{~ms}$ contact time and a $6.0 \mathrm{~s}$ delay between successive scans. Single pulse experiments were recorded with 10000 scans, and a 15 s delay between the scans. Protons were decoupled during acquisition using SPINAL-64 proton decoupling with a field strength of 80 kHz. 90 degree pulse durations and Hartmann-Hahn match for cross polarization were calibrated using $\alpha$-glycine. The spectra were processed using TopSpin 3.6 software. The longitudinal relaxation time constants $\mathrm{T} 1$ were measured using an inversion recovery 
experiment with 10-time increments, each recorded using 96 scans. Other experimental parameters were same to those used in $\mathrm{CP}$ experiments. The signal build-up after the inversion pulse at the incremented recovery delays was monitored by integrating the whole xylan signal area as one region, and the DMSO signal region separately. Fitting to the integral values was performed using the analysis package built in TopSpin software.

TEM imaging. 300 mesh copper grids coated with lacey carbon (Agar) were used. The grids were treated with a plasma cleaner (Gatan Solarus Model 950) before sample preparation. 5 $\mathrm{mg} \mathrm{ml}^{-1} \mathrm{xylan} / \mathrm{DMSO}$ dispersion was centrifuged for $5 \mathrm{~min}$ at $10000 \mathrm{rpm}$, room temperature, using Eppendorf Minispin (Sigma-Aldrich, St. Louis, United States) to separate aggregations. Then $1 \mu \mathrm{l}$ of the supernatant was applied to the grid and blotted once with filter paper for $3 \mathrm{~s}$. The sample was imaged using a FEI Tecnai 12 TEM equipped with a Gatan US1000 CCD \& SiS MegaView CCD camera.

Electron diffraction. Electron difftraction experiments were done using a Jeol JEM 2100 Plus (Jeol ltd., Japan) operated at $200 \mathrm{kV}$, with Gatan RIO16 CMOS Camera. $5 \mathrm{mg} \mathrm{ml}^{-1}$ xylan/DMSO dispersion was centrifuged for $5 \mathrm{~min}$ at 10,000 rpm at room temperature, using Eppendorf Minispin (Sigma-Aldrich, St. Louis, United States) to separate aggregates. Then 1 $\mu 1$ of the supernatant was deposited onto carbon-coated copper grid and quenched with thin DMSO layer into liquid nitrogen. The measurement was performed at -the cryogenic temperature (c.a. $-176{ }^{\circ} \mathrm{C}$ ) using a Gatan Elsa Cryo holder. The Camera length was calibrated using a powder diffraction pattern of an evaporated Al film.

X-ray diffraction was measured using SmartLab instrument (RIGAKU) operated at $45 \mathrm{~mA}$ and $200 \mathrm{kV}$ with $\mathrm{Cu}$ target $(\lambda=1.5418 \AA)$. Lyophilized xylan crystal sheets were prepared from xylan/DMSO mixture with a freeze-dryer (Martin Christ Gefriertrocknungsanlagen 
$\mathrm{GmbH}$ ) for 10 days. Diffraction data were collected in the continuous line scan mode with $\theta / 2 \theta$ geometry from $5^{\circ}$ to $60^{\circ} 2 \theta$ in two sample geometries. For a transmission geometry, the sheet sample was placed in a vertically placed sample holder where the sample surface was perpendicular to the incident X-ray beam at $2 \theta=0^{\circ}$. For a reflection geometry, the sample was placed in a horizontally placed sample holder where the sample surface was parallel to the incident X-ray beam at $2 \theta=0^{\circ}$. A diffraction profile of air without sample was collected under the same experimental condition, and it was used for the initial background subtraction from the sample. The subtracted data were smoothed using Savitzky-Golay ${ }^{59}$ filter with a window size of 29 and a polynomial order of 1 . The amorphous contribution was subtracted from remaining elastic scattering profile using a smoothing procedure applying SavitzkyGolay filter from $8^{\circ}$ to $55^{\circ} 2 \theta$ for each diffraction profile. ${ }^{60,61}$ Window size and polynomial order for the Savitzky-Golay filter were set to 201 (corresponding to $4^{\circ}$ by $2 \theta$ ) and 1 , respectively. Iteration for the background estimation was repeated for 50 times. The profiles were fitted with ten pseudo-Voigt functions using $l m f i t^{62}$ software for a range spanning from $7^{\circ}$ to $32^{\circ} 2 \theta$. The d-spacings, $d$, were calculated from the peak positions using Bragg's law and the crystal sizes were estimated from Scherrer equation:

$$
\begin{gathered}
2 d \sin \theta=\lambda \\
C W_{h k l}=\frac{K \lambda}{\beta_{h k l} \cos \theta}
\end{gathered}
$$

where $\theta$ is the peak position, $\lambda$ is the $\mathrm{X}$-ray wavelength, $K=0.90$ is shape factor, and $\beta_{h k l}$ is the full width at half maximum (FWHM) of the diffraction peak in radians.

Altogether ten peaks were identified in the two experiments with transmission and reflection geometry, Table S4. The peaks labeled peak 1, peak 4 and peak 6 were observed stronger in 
the transmission geometry than in the reflection geometry. These peaks are likely from the lattice plane parallel to the film which corresponds to a crystallographic $a b$ plane of a lamellar crystal. Indexing for the ten diffraction peaks was performed through two-step grid search approach. At first, only three strong equatorial peaks (peak 1, peak 4 and peak 6) were used to select candidates for unit cell parameters $a, b$ and $\gamma$. The list of $d_{h k l}$ was produced from monoclinic unit cell parameters $a(4 \AA \leq a \leq 20 \AA$; step $0.01 \AA), b(4 \AA \leq b \leq 20 \AA$; step $0.01 \AA)$ and $\gamma\left(90^{\circ} \leq \gamma \leq 120^{\circ}\right.$; step $\left.0.1^{\circ}\right)$ for $h k l(0<h<5,-5<k<5, l=0)$ by using $\operatorname{cctbx}$ library (Grosse-Kunstleve et al. 2002). The candidates of unit cell parameters were at first selected by the following criteria:

$$
\begin{gathered}
\max _{1 \leq i \leq 3} d_{h k l}-d_{o b s}[i]<0.005 \\
\frac{\sum_{i=1}^{3}\left(d_{h k l}-d_{o b s}[i]\right)}{3}<0.003 \\
S_{a b \gamma}<120
\end{gathered}
$$

where $d_{h k l}$ is d-spacing calculated from any $h k l$ lattice plane close to each $d_{o b s}[i]$, and $S_{a b \gamma}$ was the area of the parallelogram calculated from $a, b$ and $\gamma$. This procedure returned 79 candidates for further consideration. The 79 candidates were examined for the unit cell parameter $c(9 \AA \leq c \leq 11 \AA$; step $0.01 \AA)$ with all ten diffraction peaks, by using the following criteria:

$$
\begin{aligned}
& \max _{1 \leq i \leq 10} d_{h k l}-d_{o b s}[i]<0.06 \\
& \frac{\sum_{i=1}^{10}\left(d_{h k l}-d_{o b s}[i]\right)}{10}<0.03
\end{aligned}
$$


Finally, 8 candidates for the unit cell parameters were determined with a monoclinic unit cell, Table S3. Within these candidates, only a set of unit cell parameters agreed with the unit cell of electron diffraction. The other candidates were not further considered based on XRD. Method for powder sample diffraction (solvent exchange experiments) is present in supporting information.

GPC. $50 \mathrm{mg}$ lyophilized xylan nanocrystals were pre-activated in MilliQ water and then solvent exchanged to acetone, after which $4 \mathrm{~mL}$ of pure dimethylacetamide (DMAc) was added to the samples and left overnight. Subsequently, DMAc was removed by sequentially exposing it to vacuum several times and the solid sample was quickly transferred into $5.0 \mathrm{~mL}$ $90 \mathrm{mg} \mathrm{ml}^{-1} \mathrm{LiCl} / \mathrm{DMAc}$ at room temperature and kept agitated using magnetic stirrer. The dissolved sample was diluted 10 -fold with pure DMAc to $1 \mathrm{mg} \mathrm{ml}^{-1}$ and filtered with a 0.2 $\mu \mathrm{m}$ syringe filter for GPC analysis. The instrument consists of Dionex Ultimate 3000 HPLC module, Shodex DRI (RI-101) detector, and Viscotek/Malvern SEC/MALS 20 multi-angle light-scattering (MALS) detector. The columns used were Agilent PLgel MIXED-A $(\times 4)$. The flowrate was $0.75 \mathrm{ml} \mathrm{min}{ }^{-1}$. The injection volume was $100 \mu 1$. Detector constants (MALS and DRI) were determined using narrow polystyrene sample $\left(\mathrm{Mw}=96000 \mathrm{~g} \mathrm{~mol}^{-1}, \mathrm{Ð}=1.04\right)$ dissolved in $0.9 \% \mathrm{LiCl}$ in DMAc. A broad polystyrene sample $\left(\mathrm{Mw}=248000 \mathrm{~g} \mathrm{~mol}^{-1}, \mathrm{D}=\right.$ 1.73) was used for checking the detector calibration. The $\partial \mathrm{n} / \partial \mathrm{c}$ value of $0.136 \mathrm{ml} \mathrm{g}^{-1}$ was used for xylan in $0.9 \% \mathrm{LiCl}$ in DMAc. ${ }^{63}$ Here, the $\partial \mathrm{n} / \partial \mathrm{c}$ value determined for cellulose was used since, to our knowledge, this value has not been determined for xylan. In general, it can be assumed that the optical properties of linear polysaccharides are independent from the chemical (monosaccharide) composition. In case of $\mathrm{DMAc} / \mathrm{LiCl}$ solutions, however, the number of free hydroxyl groups in the polysaccharide structure may influence the $\partial \mathrm{n} / \partial \mathrm{c}$ value since $\mathrm{LiCl}$ interacts with hydroxyl groups. Thus, the actual $\partial \mathrm{n} / \partial \mathrm{c}$ might be slightly lower for 
xylan than for cellulose and consequently, the molar masses presented here slightly underestimated. ${ }^{64}$

\section{ASSOCIATED CONTENT}

\section{Supporting Information}

The Supporting Information is available free of charge at

Supplementary details on reagents and materials; image analysis details; ICP-AES analysis for metal elements content in raw xylan; Cryo-TEM images of XyNCs; Carbohydrate compositions in XyNCs; SEM images of raw xylan and XyNCs; single pulse NMR spectrum of raw xylan and XyNCs; TG analysis of raw xylan; TG analysis and XRD of dried XyNCs sample after washing with water, ethanol and acetone; additional figures are provided to complete Figure 5A.

\section{AUTHOR INFORMATION}

\section{Corresponding Author}

*E-mail: yoshiharu.nishiyama@cermav.cnrs.fr

*E-mail: tekla.tammelin@vtt.fi

*E-mail: eero.kontturi@aalto.fi

\section{Author Contributions}

The manuscript was written through contributions of all authors. All authors have given approval to the final version of the manuscript.

\section{Notes}

The authors declare no competing financial interests. 


\section{ACKNOWLEDGEMENT}

We gratefully thank Dr. Leena Pitkänen for the GPC analysis and Hannu Revitzer for ICPAES measurement. We acknowledge the help of Jani Seitsonen for TEM and Cryo-TEM measurement. The NanoBio-ICMG platform (FR 2607) is acknowledged for granting access to the electron microscopy facility. This work was supported by FinnCERES Academy of Finland Flagship programme (project numbers 318890 and 318891). 


\section{REFERENCES}

1. Lin, N.; Huang, J.; Dufresne, A. Preparation, Properties and Applications of Polysaccharide Nanocrystals in Advanced Functional Nanomaterials: A Review. Nanoscale 2012, 4, 3274-3294.

2. Dufresne, A. Processing of Polymer Nanocomposites Reinforced with Polysaccharide Nanocrystals. Molecules 2010, 15, 4111-4128.

3. Kontturi, E.; Laaksonen, P.; Linder, M. B.; Nonappa; Gröschel, A. H.; Rojas, O. J.; Ikkala, O. Advanced Materials through Assembly of Nanocelluloses. Adv. Mater. 2018, $30,1703779$.

4. Pereda, M.; Kissi, N. El; Dufresne, A. Extrusion of Polysaccharide Nanocrystal Reinforced Polymer Nanocomposites through Compatibilization with Poly(Ethylene Oxide). ACS Appl. Mater. Interfaces 2014, 6, 9365-9375.

5. Niinivaara, E.; Faustini, M.; Tammelin, T.; Kontturi, E. Water Vapor Uptake of Ultrathin Films of Biologically Derived Nanocrystals: Quantitative Assessment with Quartz Crystal Microbalance and Spectroscopic Ellipsometry. Langmuir 2015, 31, $12170-12176$.

6. Niinivaara, E.; Faustini, M.; Tammelin, T.; Kontturi, E. Mimicking the Humidity Response of the Plant Cell Wall by Using Two-Dimensional Systems: The Critical Role of Amorphous and Crystalline Polysaccharides. Langmuir 2016, 32, 2032-2040.

7. Tzoumaki, M. V.; Karefyllakis, D.; Moschakis, T.; Biliaderis, C. G.; Scholten, E. Aqueous Foams Stabilized by Chitin Nanocrystals. Soft Matter 2015, 11, 6245-6253.

8. Bhattacharya, T.; Bandyopadhyay, N. R.; Roy, D.; Bhattacharyya, D. K.; Bengal, W. Novel Approach to Prepare Biopolymers Based Nanocrystals. Adv. Appl. Sci. Res. 2013, 4, 251-254.

9. Bel Haaj, S.; Thielemans, W.; Magnin, A.; Boufi, S. Starch Nanocrystals and Starch 
Nanoparticles from Waxy Maize as Nanoreinforcement: A Comparative Study. Carbohydr. Polym. 2016, 143, 310-317.

10. Zheng, H.; Ai, F.; Chang, P. R.; Huang, J.; Dufresne, A. Structure and Properties of Starch Nanocrystal-Reinforced Soy Protein Plastics. Polym. Compos. 2009, 474-480.

11. Ma, X.; Li, R.; Zhao, X.; Ji, Q.; Xing, Y.; Sunarso, J.; Xia, Y. Biopolymer Composite Fibres Composed of Calcium Alginate Reinforced with Nanocrystalline Cellulose. Compos. Part A: Appl. Sci. Manuf. 2017, 96, 155-163.

12. Spoljaric, S.; Salminen, A.; Luong, N. D.; Seppälä, J. Elastic, Crosslinked Poly(Acrylic Acid) Filaments: Nanocellulose Reinforcement and Graphene Lubrication. RSC Adv. 2015, 5, 107992-108001.

13. McKee, J. R.; Huokuna, J.; Martikainen, L.; Karesoja, M.; Nykänen, A.; Kontturi, E.; Tenhu, H.; Ruokolainen, J.; Ikkala, O. Molecular Engineering of Fracture Energy Dissipating Sacrificial Bonds into Cellulose Nanocrystal Nanocomposites. Angew. Chem. Int. Ed. 2014, 53, 5049-5053.

14. Olszewska, A.; Valle-Delgado, J. J.; Nikinmaa, M.; Laine, J.; Österberg, M. Direct Measurements of Non-Ionic Attraction and Nanoscaled Lubrication in Biomimetic Composites from Nanofibrillated Cellulose and Modified Carboxymethylated Cellulose. Nanoscale 2013, 5, 11837-11844.

15. Goujon, L. J.; Hariharan, S.; Sayyar, B.; Burke, N. A. D.; Cranston, E. D.; Andrews, D. W.; Stöver, H. D. H. Tunable Hydrogel Thin Films from Reactive Synthetic Polymers as Potential Two-Dimensional Cell Scaffolds. Langmuir 2015, 31, 5623-5632.

16. Guo, J.; Filpponen, I.; Johansson, L. S.; Mohammadi, P.; Latikka, M.; Linder, M. B.; Ras, R. H. A.; Rojas, O. J. Complexes of Magnetic Nanoparticles with Cellulose Nanocrystals as Regenerable, Highly Efficient, and Selective Platform for Protein Separation. Biomacromolecules 2017, 18, 898-905. 
17. Csoka, L.; Hoeger, I. C.; Rojas, O. J.; Peszlen, I.; Pawlak, J. J.; Peralta, P. N. Piezoelectric Effect of Cellulose Nanocrystals Thin Films. ACS Macro Lett. 2012, 1, $867-870$.

18. Hänninen, A.; Rajala, S.; Salpavaara, T.; Kellomäki, M.; Tuukkanen, S. Piezoelectric Sensitivity of a Layered Film of Chitosan and Cellulose Nanocrystals. Procedia Eng. 2016, 168, 1176-1179.

19. Hakalahti, M.; Mautner, A.; Johansson, L. S.; Hänninen, T.; Setälä, H.; Kontturi, E.; Bismarck, A.; Tammelin, T. Direct Interfacial Modification of Nanocellulose Films for Thermoresponsive Membrane Templates. ACS Appl. Mater. Interfaces 2016, 8, $2923-$ 2927.

20. McKee, J. R.; Hietala, S.; Seitsonen, J.; Laine, J.; Kontturi, E.; Ikkala, O. Thermoresponsive Nanocellulose Hydrogels with Tunable Mechanical Properties. ACS Macro Lett. 2014, 3, 266-270.

21. McKee, J. R.; Appel, E. A.; Seitsonen, J.; Kontturi, E.; Scherman, O. A.; Ikkala, O. Healable, Stable and Stiff Hydrogels: Combining Conflicting Properties Using Dynamic and Selective Three-Component Recognition with Reinforcing Cellulose Nanorods. Adv. Funct. Mater. 2014, 24, 2706-2713.

22. Nitta, S. K.; Numata, K. Biopolymer-Based Nanoparticles for Drug/Gene Delivery and Tissue Engineering. Int. J. Mol. Sci. 2013, 14, 1629-1654.

23. Tersur Orasugh, J.; Dutta, S.; Das, D.; Nath, J.; Pal, C.; Chattopadhyay, D. Utilization of Cellulose Nanocrystals (CNC) Biopolymer Nanocomposites in Ophthalmic Drug Delivery System (ODDS). J. Nanotechnol. Res. 2019, 1, 75-87.

24. Scheller, H. V.; Ulvskov, P. Hemicelluloses. Annu Rev Plant Biol 2010, 61, 263-289.

25. Chanzy, H.; Dube, M.; Marchessault, R. H. Structural Polymorphism of (1-4)-/- $\beta-D-$ Xylan. Polymer 1979, 20, 1037-1039. 
26. Marchessault, R. H.; Morehead, F. F.; Walter, N. M.; Glaudemans, C. P. J.; Timell, T. E. Morphology of Xylan Single Crystals. J. Polym. Sci. 1961, 51, 66-68.

27. Nieduszynski, I.; Marchessault, R. H. Structure of $\beta$-D- (1-4') Xylan Hydrate. Nature $1971,46-47$.

28. Grimaud, F.; Pizzut-Serin, S.; Tarquis, L.; Ladevèze, S.; Morel, S.; Putaux, J. L.; Potocki-Veronese, G. In Vitro Synthesis and Crystallization of $\beta$-1,4-Mannan. Biomacromolecules 2019, 20, 846-853.

29. Hägglund, P.; Sabini, E.; Boisset, C.; Wilson, K.; Chanzy, H.; Stålbrand, H. Degradation of Mannan I and II Crystals by Fungal Endo- $\beta$-1,4-Mannanases and a $\beta$ 1,4-Mannosidase Studied with Transmission Electron Microscopy. Biomacromolecules 2001, 2, 694-699.

30. Heux, L.; Hägglund, P.; Putaux, J. L.; Chanzy, H. Structural Aspects in Semicrystalline Samples of the Mannan II Family. Biomacromolecules 2005, 6, 324-332.

31. Xiang, Z.; Jin, X.; Huang, C.; Li, L.; Wu, W.; Qi, H.; Nishiyama, Y. Water Cast Film Formability of Sugarcane Bagasse Xylans Favored by Side Groups. Cellulose 2020, 27, $7307-7320$.

32. Gordobil, O.; Egüés, I.; Urruzola, I.; Labidi, J. Xylan-Cellulose Films: Improvement of Hydrophobicity, Thermal and Mechanical Properties. Carbohydr. Polym. 2014, 112, $56-62$.

33. Hansen, N. M. L.; Plackett, D. Sustainable Films and Coatings from Hemicelluloses: A Review. Biomacromolecules 2008, 9, 1493-1505.

34. Mikkonen, K. S.; Tenkanen, M. Sustainable Food-Packaging Materials Based on Future Biorefinery Products: Xylans and Mannans. Trends Food Sci. Technol. 2012, 28, 90-102.

35. Laine, C.; Harlin, A.; Hartman, J.; Hyvärinen, S.; Kammiovirta, K.; Krogerus, B.; 
Pajari, H.; Rautkoski, H.; Setälä, H.; Sievänen, J.; Uotila, J.; Vähä-Nissi, M. Hydroxyalkylated Xylans - Their Synthesis and Application in Coatings for Packaging and Paper. Ind. Crops Prod. 2013, 44, 692-704.

36. Ebringerová, A.; Heinze, T. Xylan and Xylan Derivatives - Biopolymers with Valuable Properties, 1: Naturally Occurring Xylans Structures, Isolation Procedures and Properties. Macromol. Rapid Commun. 2000, 21, 542-556.

37. Helbert, W.; Sugiyama, J. High-Resolution Electron Microscopy on Cellulose II and $\alpha$ Chitin Single Crystals. Cellulose 1998, 5, 113-122.

38. Hiraishi, M.; Igarashi, K.; Kimura, S.; Wada, M.; Kitaoka, M.; Samejima, M. Synthesis of Highly Ordered Cellulose II in Vitro Using Cellodextrin Phosphorylase. Carbohydr. Res. 2009, 344, 2468-2473.

39. Teleman A., I. P. T. On the Accessibility and Structure of Xylan in Birch Kraft Pulp. Cellulose 2001, 8, 209-215.

40. Langan, P.; Nishiyama, Y.; Chanzy, H. X-Ray Structure of Mercerized Cellulose II at 1 Å Resolution. Biomacromolecules 2001, 2, 410-416.

41. Idström, A.; Schantz, S.; Sundberg, J.; Chmelka, B. F.; Gatenholm, P.; Nordstierna, L. 13C NMR Assignments of Regenerated Cellulose from Solid-State 2D NMR Spectroscopy. Carbohydr. Polym. 2016, 151, 480-487.

42. Kono, H.; Yunoki, S.; Shikano, T.; Fujiwara, M.; Erata, T.; Takai, M. CP/MAS 13C NMR Study of Cellulose and Cellulose Derivatives. 1. Complete Assignment of the CP/MAS 13C NMR Spectrum of the Native Cellulose. J. Am. Chem. Soc. 2002, 124, $7506-7511$.

43. Ando, I.; Asakura, T. Solid State NMR of Polymers; Elsevier: Amsterdam, 1998.

44. Schenk, W.; Reichert, D.; Schneider, H. Compatibility in Polymer Blends of Poly(Vinyl Acetate) and Poly(Methyl Methacrylate) Studied by Nuclear Magnetic 
Relaxation. Polymer 1990, 31, 329-335.

45. Busse-Wicher, M.; Gomes, T. C. F.; Tryfona, T.; Nikolovski, N.; Stott, K.; Grantham, N. J.; Bolam, D. N.; Skaf, M. S.; Dupree, P. The Pattern of Xylan Acetylation Suggests Xylan May Interact with Cellulose Microfibrils as a Twofold Helical Screw in the Secondary Plant Cell Wall of Arabidopsis Thaliana. Plant J. 2014, 79, 492-506.

46. Simmons, T. J.; Mortimer, J. C.; Bernardinelli, O. D.; Pöppler, A. C.; Brown, S. P.; DeAzevedo, E. R.; Dupree, R.; Dupree, P. Folding of Xylan onto Cellulose Fibrils in Plant Cell Walls Revealed by Solid-State NMR. Nat. Commun. 2016, 7, 13902.

47. Falcoz-Vigne, L.; Ogawa, Y.; Molina-Boisseau, S.; Nishiyama, Y.; Meyer, V.; PetitConil, M.; Mazeau, K.; Heux, L. Quantification of a Tightly Adsorbed Monolayer of Xylan on Cellulose Surface. Cellulose 2017, 24, 3725-3739.

48. Jarvis, M. C.; Apperley, D. C. Chain Conformation in Concentrated Pectic Gels: Evidence from 13C NMR. Carbohydr. Res. 1995, 275, 131-145.

49. Dweltz, N. E. The Structure of $\beta$-Chitin. Biochim Biophys Acta 1961, 51, 283-294.

50. Smondyrev, A. M.; Berkowitz, M. L. Molecular Dynamics Simulation of DPPC Bilayer in DMSO. Biophys. J. 1999, 76, 2472-2478.

51. Fidale, L. C.; Ruiz, N.; Heinze, T.; El Seoud, O. A. Cellulose Swelling by Aprotic and Protic Solvents: What Are the Similarities and Differences? Macromol. Chem. Phys. 2008, 209, 1240-1254.

52. Song, G.; Zhang, J.; Nishiyama, Y. Twisted Pseudo-Tetragonal Orthorhombic Lamellar Crystal in Cellulose/Ionic Liquid Spherulite. Cellulose 2020, 27, 5449-5455.

53. Elazzouzi-Hafraoui, S.; Nishiyama, Y.; Putaux, J. L.; Heux, L.; Dubreuil, F.; Rochas, C. The Shape and Size Distribution of Crystalline Nanoparticles Prepared by Acid Hydrolysis of Native Cellulose. Biomacromolecules 2008, 9, 57-65.

54. Lu, J.; Wang, X. J.; Ching, C. B. Effect of Additives on the Crystallization of 
Lysozyme and Chymotrypsinogen A. Cryst. Growth Des. 2003, 3, 83-87.

55. Winter, W. T.; Sarko, A. Crystal and Molecular Structure of the Amylose-DMSO Complex. Biopolymers 1974, 13, 1461-1482.

56. Fernandes, A. N.; Thomas, L. H.; Altaner, C. M.; Callow, P.; Forsyth, V. T.; Apperley, D. C.; Kennedy, C. J.; Jarvis, M. C. Nanostructure of Cellulose Microfibrils in Spruce Wood. Proc. Natl. Acad. Sci. U.S.A. 2011, 108, E1195-E1203.

57. Sundberg, A.; Sundberg, K.; Lillandt, C.; Holmbom, B. Determination of Hemicelluloses and Pectins in Wood and Pulp Fibres by Acid Methanolysis and Gas Chromatography. Nord. Pulp Pap. Res. J. 1996, 11, 216-219.

58. Willför, S.; Pranovich, A.; Tamminen, T.; Puls, J.; Laine, C.; Suurnäkki, A.; Saake, B.; Uotila, K.; Simolin, H.; Hemming, J.; Holmbom, B. Carbohydrate Analysis of Plant Materials with Uronic Acid-Containing Polysaccharides-A Comparison between Different Hydrolysis and Subsequent Chromatographic Analytical Techniques. Ind. Crops Prod. 2009, 29, 571-580.

59. Savitzky, A.; Golay, M. J. E. Smoothing and Differentiation of Data by Simplified Least Squares Procedures. Anal. Chem. 1964, 36, 1627-1639.

60. Brückner, S. Estimation of the Background in Powder Diffraction Patterns through a Robust Smoothing Procedure. J. Appl. Crystallogr. 2000, 33, 977-979.

61. Frost, K.; Kaminski, D.; Kirwan, G.; Lascaris, E.; Shanks, R. Crystallinity and Structure of Starch Using Wide Angle X-Ray Scattering. Carbohydr. Polym. 2009, 78, $543-548$.

62. Newville, M.; Ingargiola, A.; Stensitzki, T.; Allen, D. B. LMFIT: Non-Linear LeastSquare Minimization and Curve-Fitting for Python. Astrophysics Source Code Library, record ascl:1606.

63. Potthast, A.; Radosta, S.; Saake, B.; Lebioda, S.; Heinze, T.; Henniges, U.; Isogai, A.; 
Koschella, A.; Kosma, P.; Rosenau, T.; Schiehser, S.; Sixta, H.; Strlič, M.; Strobin, G.; Vorwerg, W.; Wetzel, H. Comparison Testing of Methods for Gel Permeation Chromatography of Cellulose: Coming Closer to a Standard Protocol. Cellulose 2015, $22,1591-1613$.

64. Pitkänen, L.; Sixta, H. Size-Exclusion Chromatography of Cellulose : Observations on the Low-Molar-Mass Fraction. Cellulose 2020, 9. https://doi.org/10.1007/s10570-02003419-9 
Table of Contents Graphic

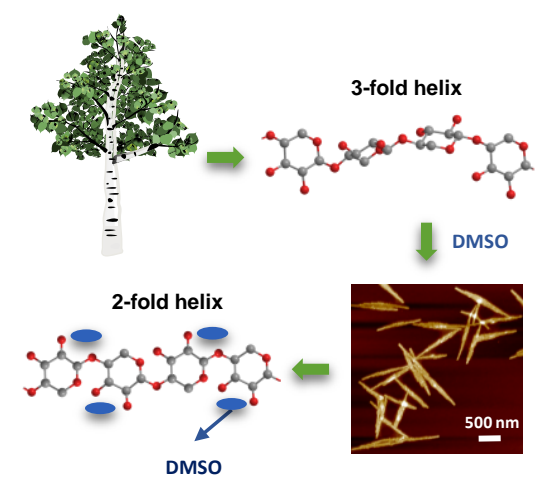

